\title{
EFEKTIVITAS IKLAN PADA MEDIA SOSIAL INSTAGRAM KOJAMA SHOP DENGAN PENDEKATAN AIDA MODEL
}

\section{ADVERTISING EFFECTIVENESS IN SOCIAL MEDIA INSTAGRAM KOJAMA SHOP WITH AIDA MODEL APPROACH}

\author{
Shilla Novira Pertiwi*, Pandi Pardian, Lucyana Trimo, Agriani Hermita Sadeli \\ Program Studi Agribisnis, Fakultas Pertanian, Universitas Padjadjaran \\ *Email: shilla17001@mail.unpad.ac.id \\ (Diterima 27-11-2020; Disetujui 29-12-2020)
}

\begin{abstract}
ABSTRAK
Perkembangan teknologi yang terus mengalami kemajuan telah dimanfaatkan oleh banyak pihak seperti para pelaku bisnis demi mempermudah aktivitas pemasaran. Teknologi yang seringkali digunakan dalam pemasaran, khususnya pada aspek promosi, ialah media sosial instagram. Salah satu pelaku bisnis yang menggunakan instagram sebagai media promosi adalah Kojama Shop yakni toko online yang menjual alpukat mentega dan buah-buahan lokal lainnya. Penelitian ini dilakukan untuk mengetahui efektivitas iklan media sosial instagram Kojama Shop. Teknik pengambilan sampel yang digunakan adalah convenience sampling dengan kriteria followers aktif instagram Kojama Shop. Penelitian ini menggunakan AIDA Model sebagai alat analisis efektivitas yang terdiri atas empat dimensi yaitu attention, interest, desire, dan action. Hasil dari penelitian ini membuktikan bahwa iklan pada instagram Kojama Shop dinilai sangat efektif dengan nilai 4,337 untuk dimensi attention, nilai 4,26 untuk dimensi interest, dan nilai 4,277 untuk dimensi desire. Sedangkan untuk dimensi action didapatkan nilai 4,117 yang berada pada kategori efektif. Adapun rekomendasi perbaikan untuk dimensi action yaitu dengan mengembangkan dan memberikan inovasi pada metode promosi untuk meningkatkan keyakinan konsumen dalam melakukan pembelian. Penelitian ini juga membuktikan bahwa nilai keseluruhan dari AIDA dinilai sangat efektif dengan nilai AIDA Rate sebesar 4,248.
\end{abstract}

Kata Kunci: Efektivitas Iklan, Instagram, AIDA Model, Kojama Shop

\begin{abstract}
Many parties such as business people have used technological developments to facilitate their marketing activities. The technology that is often used in marketing, especially in the promotional aspect, is social media instagram. One of the business players who use Instagram as a promotional media is Kojama Shop, an online shop that sells avocado butter and other local fruits. This report is written with objective of knowing the advertising effectiveness of social media instagram Kojama Shop. The sampling technique used to research was convenience sampling on Kojama Shop active followers. This research used AIDA model method which consists of four dimensions; attention, interest, desire, and action. The results prove that the advertisement on Kojama Shop instagram is considered very effective with a value of 4.337 for the attention dimension, 4.26 for the interest dimension, and 4.277 for the desire dimension. Meanwhile, it was considered effective with a value of 4.117 for the action dimension. The improvement recommendations for the action dimension are to develop and provide innovations in promotional methods to increase consumer confidence in making purchases. The results of this study also prove that the overall value of the AIDA is considered very effective with an AIDA Rate value of 4.248 .
\end{abstract}

Keywords: Advertising Effectiveness, Instagram, AIDA Model, Kojama Shop 
PENDAHULUAN

Undang Undang Republik Indonesia No. 11 Tahun 2008 telah membahas mengenai Teknologi Informasi dan Transaksi Elektronik pada pasal 4 yakni teknologi informasi dan transaksi elektronik dapat bermanfaat bagi warga negara sebagai bagian dari masyarakat informasi dunia. Dalam pasal tersebut juga disebutkan bahwa adanya pemanfaatan yang baik pada teknologi informasi dan transaksi elektronik dapat menciptakan perdagangan dan perekonomian nasional yang semakin berkembang demi mencapai kesejahteraan masyarakat. Perkembangan teknologi yang terus mengalami kemajuan telah dimanfaatkan oleh banyak pihak seperti para pelaku bisnis demi mempermudah aktivitas pemasaran produknya. Teknologi yang seringkali digunakan dalam pemasaran khususnya pada aspek promosi ialah media sosial. Dengan adanya media sosial, berbagai konten disebarkan demi terciptanya interaksi sosial yang membangun komunikasi. Salah satu media sosial yang kerap digunakan sebagai media promosi adalah media sosial Instagram.

Instagram memfasilitasi para pengguna untuk membagikan segala bentuk konten, baik dalam bentuk gambar maupun video, yang selanjutnya dapat dilihat oleh seluruh pengguna dari berbagai belahan dunia. Dengan fasilitas tersebut, pengguna dapat memanfaatkan fitur instagram untuk berbagai aspek salah satunya adalah bisnis. Instagram yang awalnya hanya ditujukan sebagai platform untuk membagikan foto kepada sesama pengguna telah mengembangkan fungsinya. Instagram dapat menjadi tempat untuk berbagi cerita, karya, ide bahkan untuk mencari pendapatan bagi para pengusaha dengan fitur Instagram for business. Fitur ini dikhususkan bagi pengguna yang menggunakan instagram sebagai media promosi. Instagram dapat membantu para pelaku bisnis untuk mempromosikan produk yang dijual dengan cara membagikan konten serta mengiklankan produk tersebut agar produk yang dijual dapat dilihat oleh banyak pengguna tanpa memakan biaya yang besar.

Menurut Bearden dan Ingram (2007), iklan ialah elemen komunikasi pemasaran yang persuasif, non personal, dibayar oleh sponsor, dan disebarkan melalui saluran komunikasi massa untuk mempromosikan pemakaian barang atau jasa. Iklan saat ini telah menjadi komunikasi yang sangat mempengaruhi pola pikir dan tingkah laku konsumen serta akan berpengaruh pada perubahan perilaku konsumen. Periklanan yang dilakukan melalui berbagai media 


\section{EFEKTIVITAS IKLAN PADA MEDIA SOSIAL INSTAGRAM KOJAMA SHOP \\ DENGAN PENDEKATAN AIDA MODEL}

Shilla Novira Pertiwi, Pandi Pardian, Lucyana Trimo, Agriani Hermita Sadeli

bertujuan agar produk yang diiklankan menjadi lebih dikenal serta akan meningkatkan daya tarik konsumen. Salah satu pelaku bisnis buah-buahan yang memanfaatkan media sosial Instagram sebagai media promosi untuk beriklan ialah Kojama Shop yakni sebuah bisnis online yang menjual alpukat mentega dengan kualitas premium dan juga beberapa produk buah-buahan lokal lainnya. Kojama merupakan penjual alpukat mentega online di instagram dengan pengikut instagram terbanyak jika dibandingkan dengan para pesaingnya pada produk sejenis.

Penjualan alpukat mentega Shop terbilang baik jika dilihat pada penjualan di e-commerce seperti Shopee dan Tokopedia. Kojama Shop mendapatkan penilaian 4,6 dari 5, mendapatkan predikat star seller serta telah menjual lebih dari 13.000 produk pada platform Shopee yang menandakan bahwa Kojama Shop memang sudah memiliki "brand" yang dikenal oleh masyarakat. Maka dari itu, penelitian ini ingin melihat dan membuktikan bahwa pemasaran yang dilakukan oleh Kojama Shop, dalam hal ini promosi dan iklan, memang terbilang baik dan efektif sehingga mampu meningkatkan minat konsumen untuk mengkonsumsi alpukat, salah satunya adalah alpukat mentega.
Promosi yang dilakukan oleh Kojama Shop tentunya bertujuan untuk menarik minat pembeli untuk melakukan pembelian. Maka dari itu, promosi Kojama Shop yang dalam hal ini adalah iklan di instagram Kojama Shop harus dapat memenuhi kriteria-kriteria tertentu seperti iklan dapat memberikan perhatian bagi para followers, iklan dapat membuat followers tertarik untuk mengetahui lebih lanjut akan produk alpukat mentega yang dijual, iklan dapat meyakinkan followers untuk memiliki produk tersebut dan akhirnya followers akan memutuskan untuk membeli produk tersebut. Penelitian ini bertujuan untuk mengetahui karakteristik pengikut instagram Kojama Shop dan juga untuk mengetahui serta mengukur tingkat efektivitas iklan media sosial instagram Kojama Shop jika dianalisa menggunakan AIDA Model.

\section{METODE PENELITIAN}

Penelitian ini dilakukan di toko online Kojamashop yang terletak di Jakarta Timur. Pemilihan Kojama Shop sebagai objek penelitian dilakukan sengaja karena adanya beberapa pertimbangan, yaitu meliputi: 1) Kojama Shop merupakan toko online yang menjual produk pertanian yaitu alpukat mentega, 2) Kojama Shop menggunakan 


\section{EFEKTIVITAS IKLAN PADA MEDIA SOSIAL INSTAGRAM KOJAMA SHOP \\ DENGAN PENDEKATAN AIDA MODEL \\ Shilla Novira Pertiwi, Pandi Pardian, Lucyana Trimo, Agriani Hermita Sadeli}

media sosial salah satunya instagram sebagai media untuk beriklan.

Penelitian ini merupakan penelitian kuantitatif yaitu metode penelitian yang berlandaskan pada filsafat positivisme, digunakan untuk meneliti pada populasi dan sampel tertentu, pengumpulan data menggunakan instrumen penelitian, analisis data bersifat kuantitatif/statistik, dengan tujuan untuk menguji hipotesis yang telah ditetapkan (Sugiyono, 2012:8). Penelitian ini dilakukan dengan metode survey dan analisis deskriptif. Alat analisis yang digunakan pada penelitian ini adalah AIDA Model. AIDA Model menurut Duncan (2005) adalah pengukuran atas dampak atau efek dari komunikasi yang terjadi pada seseorang setelah proses penerimaan pesan yang terdiri atas empat tahapan yaitu Attention (Perhatian), Interest (Ketertarikan), Desire (Minat), dan Actiond(tAeimdakanłdalah elemen yang mengukur seberapa besar iklan dapat menarik perhatian konsumen terhadap produk yang ditawarkan serta sejauh mana pelanggan akan sadar terhadap produk tersebut. Interest adalah elemen yang mengukur ketertarikan konsumen terhadap produk tersebut serta dimana minat produk tersebut akan berkembang. Desire adalah elemen yang mengukur keyakinan konsumen untuk memiliki produk tersebut serta sejauh mana pelanggan menginginkan produk tersebut. Action adalah elemen yang mengukur pengambilan aksi konsumen dalam pengambilan keputusan dalam pembelian.

Keempat dimensi tersebut diolah dengan mencari skor rata-rata menggunakan rumus sebagai berikut (Durianto dkk, 2003):

$$
x=\frac{\sum f i . w i}{\sum f i}
$$

Keterangan:

$x=$ Rata-rata bobot

fi $\quad=$ Frekuensi

$w i=$ Bobot

Posisi tanggapan responden ditentukan dengan menggunakan rentang skala penilaian. Penentuan rentang skala penilaian didapatkan dengan menggunakan skor setiap variabel. Posisi digambarkan dari posisi negatif ke positif melalui bobot alternatif yang terbentuk dari teknik skala peringkat yakni kisaran 1 sampai 5 . Adapun rumus yang digunakan untuk menentukan rentang skala yakni sebagai berikut:

$$
\mathrm{Rs}=\frac{\mathrm{R} \text { (bobot) }}{M}
$$

Keterangan:

$\mathrm{R}$ (bobot) = Bobot terbesar - bobot terkecil

$\mathrm{M} \quad=$ Banyaknya kategori bobot 


\section{EFEKTIVITAS IKLAN PADA MEDIA SOSIAL INSTAGRAM KOJAMA SHOP \\ DENGAN PENDEKATAN AIDA MODEL}

Shilla Novira Pertiwi, Pandi Pardian, Lucyana Trimo, Agriani Hermita Sadeli

Dengan menggunakan rumus di atas, rentang skala penilaian yang didapat adalah sebagai berikut:

$$
\mathrm{Rs}=\frac{5-1}{5}=0,8
$$

Sehingga didapatkan posisi keputusannya sebagaimana terlihat pada Tabel 1.

Tabel 1. Rentang Skala Keputusan AIDA Model

\begin{tabular}{ccc}
\hline No & Rentang Skala & $\begin{array}{c}\text { Kriteria } \\
\text { Keputusan }\end{array}$ \\
\hline 1 & $1,00<\mathrm{x} \leq 1,80$ & $\begin{array}{c}\text { Sangat Tidak } \\
\text { Efektif }\end{array}$ \\
2 & $1,80<\mathrm{x} \leq 2,60$ & Tidak Efektif \\
3 & $2,60<\mathrm{x} \leq 3,40$ & Cukup Efektif \\
4 & $3,40<\mathrm{x} \leq 4,20$ & Efektif \\
5 & $4,20<\mathrm{x} \leq 5,00$ & Sangat Efektif \\
\hline \multicolumn{2}{l}{ Sumber: Data Primer Diolah $(2020)$}
\end{tabular}

Penelitian ini menggunakan data kuantitatif sebagai fokus utama serta data kualitatif sebagai data pendukung.

Data kuantitatif didapatkan melalui kuesioner yang dibagikan secara online. Kuesioner menggunakan metode skala likert dan disebarkan menggunakan metode convenience sampling kepada 100 responden yang merupakan pengikut aktif instagram Kojama Shop, dan pernah memberikan like/comment/share pada unggahan iklan yang diunggah melalui instagram Kojama Shop. Karena jumlah followers yang terus bertambah, maka peneliti tidak dapat data yang valid mengenai jumlah populasi. Maka, ukuran populasi dari penelitian ini dapat dikatakan tidak terhingga. Adapun cara perhitungannya menurut Rao Purba (2006) dalam Sulistyowati dan Nursanti (2014:9) yakni sebagai berikut:

$$
\mathrm{n}=\frac{Z^{2}}{4(M o e)^{2}}
$$

Keterangan:

$\mathrm{n}=$ Ukuran sampel

$\mathrm{Z}=1,96$ score pada tingkat signifikansi tertentu (derajat keyakinan ditentukan $95 \%)$

Moe $=$ Margin of error, tingkat kesalahan maksimum adalah 10\%

Data kualitatif didapatkan dengan melakukan wawancara dengan pihak Kojamashop. Studi kepustakaan pengumpulan data dengan cara mengkaji dan mengambil referensi dari literature, buku, jurnal serta penelitian sebelumnya. Teknik analisis data yang digunakan adalah program aplikasi statistik yaitu software SPSS (Statistic for Prodict and Service Solution) for Windows versi 22 untuk pengukuran uji validitas dan uji reliabilitas.

\section{HASIL DAN PEMBAHASAN}

\section{Karakteristik Pengikut Instagram}

Hasil penelitian melalui metode yang telah ditetapkan melalui penyebaran 100 kuesioner kepada pengikut aktif Instagram Kojama Shop tertera pada Tabel 2. 


\section{EFEKTIVITAS IKLAN PADA MEDIA SOSIAL INSTAGRAM KOJAMA SHOP \\ DENGAN PENDEKATAN AIDA MODEL}

Shilla Novira Pertiwi, Pandi Pardian, Lucyana Trimo, Agriani Hermita Sadeli

Tabel 2. Karakteristik Followers

\begin{tabular}{|c|c|c|c|}
\hline No & $\begin{array}{l}\text { Karateristik } \\
\text { Followers }\end{array}$ & Jumlah & $\begin{array}{c}\text { Persentas } \\
\text { e }\end{array}$ \\
\hline \multirow[t]{3}{*}{1} & \multicolumn{3}{|c|}{ Jenis Kelamin } \\
\hline & - Laki - Laki & 22 & $22 \%$ \\
\hline & - Perempuan & 78 & $78 \%$ \\
\hline \multirow[t]{6}{*}{2} & \multicolumn{3}{|c|}{ Usia } \\
\hline & - $<21$ & 4 & $4 \%$ \\
\hline & - $21-30$ & 74 & $74 \%$ \\
\hline & - $31-40$ & 9 & $9 \%$ \\
\hline & - $41-50$ & 7 & $7 \%$ \\
\hline & - $>50$ & 6 & $6 \%$ \\
\hline \multirow[t]{3}{*}{3} & \multicolumn{3}{|c|}{ Domisili } \\
\hline & - Jakarta & 59 & $59 \%$ \\
\hline & - Luar Jakarta & 41 & $41 \%$ \\
\hline \multirow[t]{7}{*}{4} & \multicolumn{3}{|c|}{ Status Pekerjaan } \\
\hline & $\begin{array}{l}\text { - Pelajar/Mahasisw } \\
\mathrm{a}\end{array}$ & 32 & $32 \%$ \\
\hline & - Karyawan & 36 & $36 \%$ \\
\hline & - Wirausaha & 11 & $11 \%$ \\
\hline & - Wiraswasta & 2 & $2 \%$ \\
\hline & - Pegawai Negeri & 1 & $1 \%$ \\
\hline & - Lainnya & 18 & $18 \%$ \\
\hline
\end{tabular}

Sumber: Data Primer Diolah (2020)

Produk alpukat mentega yang dijual oleh Kojama Shop membuat perempuan mendominasi akun media sosial instagram Kojama Shop karena Kojama Shop kerap memberikan informasi mengenai manfaat mengkonsumsi alpukat mentega yakni sangat cocok untuk perempuan yang sedang menjalani program kehamilan atau yang sedang mengandung. Followers dengan usia 21 - 30 tahun mendominasi karena umumnya seorang perempuan yang akan menikah, baru menikah, tengah mengandung dan sedang memiliki anak bayi sangat tertarik untuk mencari tahu makanan maupun minuman yang cocok untuk gaya hidup sehat lewat media sosial instagram. Followers yang tinggal di
Jakarta lebih tertarik untuk membeli produk tersebut karena produk dapat langsung diantar menggunakan pengiriman barang dan langsung sampai pada hari itu juga sehingga meminimalisir adanya kerusakan. Selanjutnya, Karyawan mendominasi karena mereka memiliki kegiatan harian yang cukup sibuk dan lebih banyak menghabiskan waktu di kantor sehingga mereka tidak mempunyai cukup waktu luang untuk membeli alpukat secara langsung di pasar.

\section{Analisis Attention (Perhatian)}

\section{Terhadap Iklan}

Tabel 3. Skor Dimensi Attention (Perhatian)

\begin{tabular}{cccc}
\hline No & $\begin{array}{c}\text { Dimensi } \\
\text { Attention }\end{array}$ & Skor & Keterangan \\
\hline 1 & Attention 1 & 4,42 & Sangat Efektif \\
2 & Attention 2 & 4,40 & Sangat Efektif \\
3 & Attention 3 & 4,23 & Sangat Efektif \\
4 & Attention 4 & 4,03 & Efektif \\
\hline & Rata-Rata & 4,337 & Sangat Efektif
\end{tabular}

Sumber: Analisis Data Primer (2020)

Berdasarkan perolehan hasil yang didapatkan melalui penyebaran kuesioner, iklan Kojama Shop di instagram adalah iklan yang sangat efektif dalam menarik perhatian followers dengan menampilkan gambar produk yang ditunjukan dengan perolehan nilai skor 4,42. Begitu pula dengan tampilan warna yang cerah dan tulisan atau headline pada gambar iklan Kojama Shop di instagram yang sangat efektif dalam menarik perhatian dengan 


\section{EFEKTIVITAS IKLAN PADA MEDIA SOSIAL INSTAGRAM KOJAMA SHOP \\ DENGAN PENDEKATAN AIDA MODEL}

Shilla Novira Pertiwi, Pandi Pardian, Lucyana Trimo, Agriani Hermita Sadeli

nilai skor 4,40 . Selanjutnya dinyatakan bahwa iklan Kojama Shop di instagram adalah iklan yang menggunakan endorse selebritis atau selebgram untuk promosi produk dan sangat efektif dalam menarik perhatian followers dengan nilai skor 4,23. Kemudian, frekuensi unggahan iklan Kojama Shop di instagram terbilang efektif untuk membuat followers dapat mengingat produk yang dijual yang ditujukan dengan nilai skor 4,03. Sehingga, perolehan hasil untuk tahap attention secara keseluruhan adalah sebesar 4,337 yang berada pada rentang 4,20- 5,00 yaitu pada kategori "Sangat Efektif" dan dapat dikatakan bahwa pada tahap attention iklan Kojama Shop pada media sosial instagram sangat efektif untuk membuat konsumen menaruh perhatian saat iklan tersebut mucul di media sosial instagram. Sesuai dengan konsep AIDA, tahapan attention merupakan tahap pertama yang menjadi dasar sehingga tahapan ini menjadi penentu sebelum menuju ke tahapan-tahapan selanjutnya.

\section{Analisis Interest (Ketertarikan)}

\section{Terhadap Iklan}

Tabel 4. Skor Dimensi Interest (Ketertarikan)

\begin{tabular}{cccc}
\hline No & $\begin{array}{c}\text { Dimensi } \\
\text { Interest }\end{array}$ & Skor & Keterangan \\
\hline 1 & Interest 1 & 4,11 & Efektif \\
2 & Interest 2 & 4,30 & Sangat Efektif \\
3 & Interest 3 & 4,37 & Sangat Efektif \\
\hline \multicolumn{2}{c}{ Rata-Rata } & 4,26 & Sangat Efektif \\
\hline
\end{tabular}

Sumber: Analisis Data Primer (2020)
Berdasarkan perolehan hasil yang didapatkan melalui penyebaran kuesioner, iklan Kojama Shop di instagram adalah iklan yang menjelaskan manfaat produk untuk kesehatan dan efektif untuk membuat followers tertarik yang ditunjukan dengan nilai skor 4,11. Iklan Kojama Shop di instagram juga merupakan iklan yang menyampaikan pesan testimoni untuk meyakinkan keunggulan dari produk dan sangat efektif untuk membuat followers tertarik dengan produk yang ditunjukkan dengan nilai skor 4,30. Kemudian, iklan Kojama Shop di instagram merupakan iklan yang mendeskripsikan produknya dengan jelas dan dapat dipercaya serta sangat efektif untuk membuat followers tertarik yang ditunjukkan dengan nilai skor 4,37. Sehingga, perolehan hasil untuk tahap interest secara keseluruhan adalah sebesar 4,26 yang berada pada rentang 4,20- 5,00 yaitu pada kategori "Sangat Efektif" serta dapat dikatakan bahwa pada tahap interest iklan produk Kojama Shop melalui media sosial instagram sangat efektif untuk memunculkan minat konsumen terhadap produk yang diiklankan. 


\section{EFEKTIVITAS IKLAN PADA MEDIA SOSIAL INSTAGRAM KOJAMA SHOP \\ DENGAN PENDEKATAN AIDA MODEL}

Shilla Novira Pertiwi, Pandi Pardian, Lucyana Trimo, Agriani Hermita Sadeli

Analisis Desire (Keinginan) Terhadap

Iklan

Tabel 5. Skor Dimensi Desire (Keinginan)

\begin{tabular}{cccc}
\hline No & $\begin{array}{c}\text { Dimensi } \\
\text { Desire }\end{array}$ & Skor & Keterangan \\
\hline 1 & Desire 1 & 4,27 & Sangat Efektif \\
2 & Desire 2 & 4,43 & Sangat Efektif \\
3 & Desire 3 & 4,13 & Efektif \\
\hline \multicolumn{2}{c}{ Rata-Rata } & 4,277 & Sangat Efektif \\
\hline
\end{tabular}

Sumber: Analisis Data Primer (2020)

Berdasarkan perolehan hasil yang didapatkan melalui penyebaran kuesioner, caption pada iklan Kojama Shop di instagram adalah iklan yang menyampaikan informasi mengenai keunggulan produk sehingga sangat efektif untuk membuat para followersnya menginginkan produk yang ditunjukkan dengan nilai skor 4,27. Caption pada iklan Kojama Shop di instagram juga secara efektif menampilkan alasan untuk mengkonsumsi produk yang ditunjukkan dengan nilai skor 4,13. Kemudian, iklan Kojama Shop di instagram adalah iklan yang sangat efektif dalam membangkitkan keinginan followers untuk mengkonsumsi produk yang ditunjukkan dengan nilai skor 4,43. Sehingga, perolehan hasil untuk tahap desire secara keseluruhan adalah sebesar 4,277 yang berada pada rentang 4,205,00 yaitu pada kategori "Sangat Efektif" serta dapat dikatakan bahwa iklan Kojama Shop di media sosial instagram sangat efektif dalam menimbulkan keinginan responden untuk mengkonsumsi produk Kojama Shop setelah melihat iklan Kojama Shop di media sosial instagram.

\section{Analisis Action (Tindakan) Terhadap}

\section{Iklan}

Tabel 6. Skor Dimensi Action (Tindakan)

\begin{tabular}{cccc}
\hline No & $\begin{array}{c}\text { Dimensi } \\
\text { Action }\end{array}$ & Skor & Keterangan \\
\hline 1 & Action 1 & 3,78 & Efektif \\
2 & Action 2 & 4,17 & Efektif \\
3 & Action 3 & 4,40 & Sangat Efektif \\
\hline \multicolumn{2}{c}{ Rata-Rata } & 4,117 & Efektif \\
\hline
\end{tabular}

Sumber: Analisis Data Primer (2020)

Tahap action merupakan tahap penentu dalam tujuan iklan, yaitu adanya penentuan apakah konsumen melakukan tindakan pembelian atau tidak. Berdasarkan perolehan hasil yang didapatkan melalui penyebaran kuesioner, iklan Kojama Shop di instagram adalah iklan yang secara efektif menyampaikan pesan untuk memerintahkan pembelian produk yang ditunjukkan dengan nilai skor 3,78. Iklan Kojama Shop di instagram juga secara efektif menampilkan tampilan yang sesuai dengan produk sehingga followers melakukan pembelian yang ditunjukkan dengan nilai skor sebesar 4,17. Kemudian, iklan Kojama Shop di instagram merupakan iklan yang sangat efektif dalam meyakinkan responden untuk melakukan pembelian produk yang ditunjukkan dengan nilai skor 


\section{EFEKTIVITAS IKLAN PADA MEDIA SOSIAL INSTAGRAM KOJAMA SHOP \\ DENGAN PENDEKATAN AIDA MODEL}

Shilla Novira Pertiwi, Pandi Pardian, Lucyana Trimo, Agriani Hermita Sadeli

sebesar 4,40. Sehingga, perolehan hasil untuk tahap action adalah sebesar 4,117 yang berada pada rentang 3,40- 4,20 yaitu pada kategori "Efektif" serta dapat dikatakan bahwa iklan produk Kojama Shop melalui media sosial instagram efektif membuat followers melakukan pembelian produk yang diiklankan.

\section{Analisis AIDA Rate}

Setelah masing-masing variabel dalam AIDA dianalisis dan dihitung rata-ratanya, selanjutnya adalah melakukan perhitungan berdasarkan keseluruhan konsep AIDA untuk mengetahui jumlah rata-rata ahkir. Secara keseluruhan tabel skor keempat dimensi AIDA dapat dilihat pada tabel 7.

Tabel 7. Skor AIDA Rate

\begin{tabular}{cccc}
\hline \multirow{2}{*}{ No } & AIDA & Skor & Keterangan \\
& Model & & \\
\hline 1 & Attention & 4,337 & Sangat Efektif \\
2 & Interest & 4,26 & Sangat Efektif \\
3 & Desire & 4,277 & Sangat Efektif \\
4 & Action & 4,227 & Efektif \\
\hline \multicolumn{2}{c}{ AIDA Rate } & 4,248 & Sangat Efektif \\
\hline
\end{tabular}

Sumber: Analisis Data Primer (2020)

Hasil rata-rata keseluruhan AIDA berada pada rentang skala 4,20 - 5,00 yaitu "Sangat Efektif ". Secara keseluruhan dari Konsep AIDA, iklan alpukat mentega Kojama Shop sangat efektif dalam meyakinkan konsumen mulai dari saat konsumen pertama kali melihat iklan, mengenal produk hingga akhirnya memutuskan untuk membeli produk. Keseluruhan grafik hasil analisis efektivitas iklan media sosial instagram Kojama Shop dengan pendekatan AIDA Model tersaji pada Gambar 1.

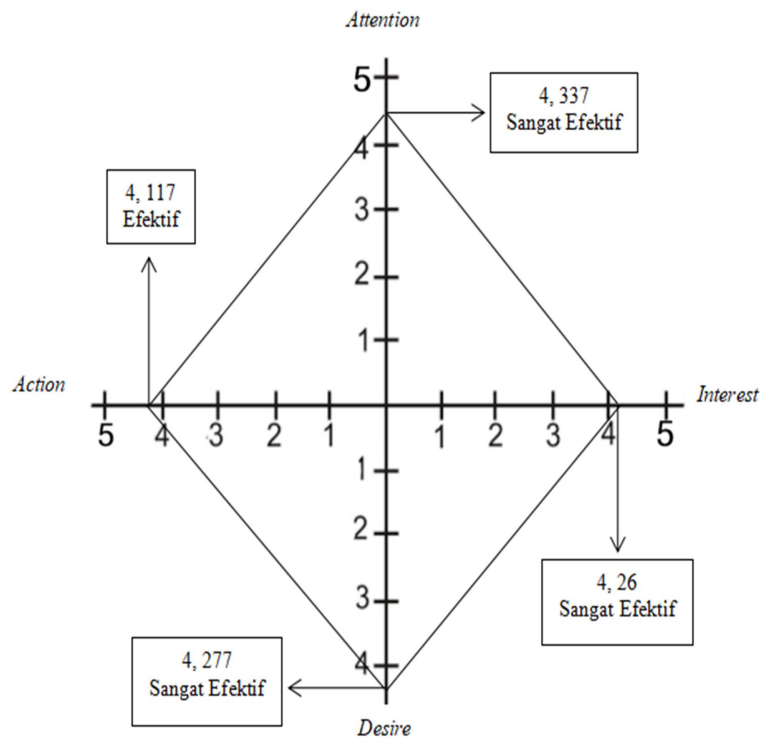

Gambar 1. AIDA Model Iklan Kojama Shop pada Media Sosial Instagram

\section{KESIMPULAN DAN SARAN}

\section{Kesimpulan}

Secara keseluruhan, efektivitas iklan Kojama Shop pada media sosial instagram jika diukur dengan menggunakan AIDA Model berada pada kategori "Sangat Efektif" dengan hasil skor rata-rata 4,248. Dimensi yang memiliki nilai tertinggi adalah attention (perhatian) dengan nilai skor 4,337, lalu diikuti dengan dimensi desire dengan nilai skor 4,277, kemudian dilanjutkan dengan dimensi interest dengan nilai skor 4,26, dan dimensi dengan nilai skor 
terkecil adalah action dengan nilai skor 4,117 .

Jadi dapat disimpulkan bahwa iklan alpukat mentega Kojama Shop sangat efektif dalam meyakinkan konsumen mulai dari saat konsumen pertama kali melihat iklan, mengenal produk hingga akhirnya memutuskan untuk membeli produk.

\section{Saran}

Berdasarkan kesimpulan yang didapatkan, nilai rata-rata untuk skor dimensi action lebih kecil dibandingkan dengan dimensi lainnya sehingga perlu adanya peningkatan kinerja serta evaluasi yang berkaitan dengan variabel action. Upaya-upaya yang dapat dilakukan adalah sebagai berikut:

1. Meningkatkan dan mengembangkan promosi yang berkaitan dengan cara Kojama Shop memerintah/mengajak konsumen untuk membeli produk.

2. Menambah promo-promo yang menarik konsumen untuk membeli produk seperti memberi bonus produk buah-buahan lain setiap pembelian produk alpukat mentega.

3. Menginovasi bentuk packaging.
4. Memberikan promo bundling product pada sesama produk buah-buahan yang dijual di Kojama Shop.

\section{DAFTAR PUSTAKA}

Bearden, William O., Thomas N Ingram and Raymond W LaForge. 2007. Marketing: principles \& perspectives (5th ed). New York: McGraw-HillBorden, N. H. (1964). The concept of the marketing mix. Journal of advertising research, 4(2), 2-7.

Duncan, T. (2005). Principles of advertising \& IMC. McGraw-Hill/Irwin.

Durianto, D., Sugiarto, A. W., \& Hendrawan, S. (2003). Invasi pasar dengan iklan yang efektif. Jakarta: $\quad P T$ Gramedia pustaka utama.

Sugiyono. (2012). Metode Penelitian Kuantitatif Kualitatif dan R\&D. Bandung: ALFABETA, $C V$.

Sulistyowati, L., \& Nursanti, A. (2014). Analisis Pengaruh Kreativitas Iklan, Daya Tarik Iklan dan Kredibilitas Endorser terhadap Brand Attitude pada Produk Handphone Android di Kota Pekanbaru. Jurnal Ekonomi, 22(01), 132-149.

Undang-Undang Republik Indonesia Nomor 11 Tahun 2008 Informasi dan Transaksi Elektronik. 21 April 2008. Lembaran Negara Republik Indonesia Tahun 2008 Nomor 58. Jakarta. 